\author{
Timo Krings \\ Franz-Josef Hans \\ Sasikhan Geibprasert \\ Karel Terbrugge
}

\section{Partial "targeted" embolisation of brain arteriovenous malformations}

Received: 9 February 2010

Revised: 11 April 2010

Accepted: 16 April 2010

Published online: 11 June 2010

(C) The Author(s) 2010.

This article is published with open access at Springerlink.com

T. Krings $(\bullet) \cdot \mathrm{K}$. Terbrugge

Division of Neuroradiology, Department of

Medical Imaging,

University of Toronto, Toronto Western

Hospital, UHN,

399 Bathurst St., 3MCL-429, Toronto, ON

M5T 2S8, Canada

e-mail: timo.krings@uhn.on.ca

Tel.: +1-416-6035562

Fax: +1-416-6034257

T. Krings $\cdot$ F.-J. Hans

Department of Neurosurgery,

University Hospital Aachen, Aachen, Germany

T. Krings $\cdot$ S. Geibprasert

The Service de Neuroradiologie

Diagnostique et Therapeutique, CHU,

Le-Kremlin-Bicetre, Paris, France
S. Geibprasert

Department of Diagnostic Imaging,

Division of Neuroradiology, the Hospital for

Sick Children,

University of Toronto, Toronto, ON, Canada

S. Geibprasert

Department of Radiology, Ramathibodi

Hospital,

Mahidol University, Bangkok, Thailand

\begin{abstract}
The treatment of pial arteriovenous brain malformations is controversial. Little is yet known about their natural history, their pathomechanisms and the efficacy and risks of respective proposed treatments. It is known that only complete occlusion of the AVM can exclude future risk of haemorrhage and that the rates of curative embolisation of AVMs with an acceptable periprocedural risk are around 20 to $50 \%$. As outlined in the present article,
\end{abstract}

however, partial, targeted embolisation also plays a role. In acutely ruptured AVMs where the source of bleeding can be identified, targeted embolisation of this compartment may be able to secure the AVM prior to definitive treatment. In unruptured symptomatic AVMs targeted treatment may be employed if a defined pathomechanism can be identified that is related to the clinical symptoms and that can be cured with an acceptable risk via an endovascular approach depending on the individual AVM angioarchitecture. This review article gives examples of pathomechanisms and angioarchitectures that are amenable to this kind of treatment strategy.

Keywords Brain AVM .

Embolisation · Epilepsy ·

Haemorrhage · Pathomechanism

\section{Introduction}

For brain pial arteriovenous malformations, too little is as of yet known concerning their aetiology, pathophysiology and natural history to truly and confidently give guidelines for their treatment. Both advances in diagnostic tools for pretreatment risk assessment and continuously improved treatment techniques such as catheterisation and embolisation materials will presumably change therapeutic risks and will therefore have an impact on the way we will manage these vascular malformations. Finally, the skills and experience of the physician performing the endovascular treatment have a profound impact on the patient's outcome, which will therefore naturally vary from centre to centre.

In this article, we will nevertheless try to describe our current approach to pial arteriovenous brain malformations that is based on an attempt to relate the patient's clinical findings to the underlying angioarchitecture in order to define angiographic targets related to the pertinent individual pathophysiology [1]. We will, therefore, first briefly describe a classification of vascular malformations in general, and of brain AVMs in particular, followed by a description of angioarchitectural points to consider when treating brain AVMs. In the last part of this article, we will describe our 
current concept of treatment, which has been coined "partial targeted" embolisation of brain AVMs.

\section{Classification of vascular malformations in general}

A classification of pial brain AVMs that is based upon the size, the pattern of venous drainage and the eloquence of the portions of brain adjacent to the AVM [2] is of limited use when considering an endovascular treatment. First, such classification cannot predict the natural history of a specific AVM for an individual patient; second, it does not anticipate the risk of treating brain AVMs by endovascular techniques; third, it does not enhance our understanding of this disease.

Concerning the latter, a classification that is based upon the aetiology of vascular malformations may be a more useful approach to assessing vascular malformative diseases in general, of which arteriovenous malformations are but a subgroup [3]. This aetiological classification takes into account the target, the timing, and the nature of the triggering event $[4,5]$. Because arteries and veins are already differentiated early during vasculogenesis, the target of a triggering event may vary depending on its location along the vessel tree: Arteries, the arteriovenous junction at the capillary level, veins, and lymphatic vessels are molecularly distinct vascular channels and therefore different targets [4]. The second determinant will be the timing when the trigger hits its target: an early hit during vasculogenesis (such as a germinal mutation) will affect more cells and will lead to a metamerically arranged defect, whereas a late hit (such as a somatic mutation that occurs late during the fetal life or even postnatally) will have a more focal impact on the vessel [3]. Finally, the nature of the triggering event (intrinsic, i.e., genetic vs. extrinsic, i.e., environmental, traumatic or infectious) will add another level of complexity to this schematic approach of classifying brain vascular malformations [6]. Although there is likely to be a continuous spectrum of vascular diseases rather than clear-cut disease entities, the scheme that is based on the above-mentioned assumptions may help to discern vascular malformations from an aetiological standpoint [7].

The main focus of this article will be on the endovascular treatment of the shunting lesions. While the above-mentioned classification may be helpful to broadly categorise vascular lesions, the most frequently encountered shunting malformation i.e., the pial brain AVMs, deserve further subclassification as the presented classification is too crude to predict the natural history of a specific AVM for an individual patient and is unable to anticipate the endovascular treatment risk [8].

\section{Classification of brain AVMs based on their natural history}

A classification that is aimed at predicting the natural history has to distinguish first those AVMs that have bled from those that have not bled, which in most instances will be possible by the review of the clinical history. In asymptomatic patients, T2-weighted gradient echo sequences, which are highly susceptible to depicting signs of old haemorrhage, may assist in identifying those exceedingly rare cases in which a subclinical haemorrhage may have occurred [9]. The future risk of bleeding from a brain AVM has been the subject of many studies. In 1983, Graf et al. published their results concerning the risk of future haemorrhage, which were calculated to be $37 \%$ in 20 years for unruptured AVMs and $47 \%$ for ruptured AVMs [10]. Crawford et al. found similar 20-year cumulative risks of haemorrhage (33\% for unruptured and $51 \%$ for ruptured AVMs); however, they added that more advanced age was a major risk factor, with patients older than 60 years harbouring a risk of rupture of $90 \%$ in 9 years [11]. Both studies demonstrated an annual average risk of haemorrhage of approximately $2 \%$, which was confirmed in the study in 1988 of Brown et al. who investigated unruptured AVMs only [12]. He added that the risk of permanent morbidity and mortality following a haemorrhage of a brain AVM was $29 \%$ and $23 \%$, respectively. Ondra et al. in 1990 calculated a slightly higher risk of $5 \% / y e a r$ for unruptured brain AVMs with a mortality risk of $1 \%$ per year (i.e., $25 \%$ for all haemorrhages) and a morbidity of $2.7 \% /$ year (more than $50 \%$ for all haemorrhages) [13]. In a prospective series published by Mast et al. in 1997, the yearly risk of haemorrhage for previously ruptured brain AVMs was calculated as $17 \%$ per year, whereas in unruptured AVMs, the risk of haemorrhage was $2 \%$ per year [14]. They found male gender, deep venous drainage and previous haemorrhages to be the major determinants of future haemorrhages.

\section{Patho-mechanical classification of brain AVMS}

While there is, therefore, little discussion about the necessity of treating pial AVMs that have bled because of their larger rebleeding risk, pial AVMs that have not bled have to be further subdivided to select those patients in whom therapy is indicated, i.e., in whom the therapeutic risk is lower than the natural history risk. At present a randomized trial is underway that tries to elucidate the risks of treatment compared to a conservative management. In this trial, which was coined ARUBA (A Randomized Trial of Unruptured Brain AVMs), subjects with unruptured AVMs are randomly assigned to either best possible invasive therapy (endovascular, neurosurgical and/or radiation therapy) or medical management without intervention. Patients will be followed for 5 to a maximum of 10 years to get a better understanding of the natural history and the treatment-related risks [15].

In our practice, we try to classify "unruptured" AVMs according to their pathomechanism (printed subsequently in italics) in relation to the angioarchitecture and imaging findings and thereby decide on the necessity of treatment. Due to their high-flow shunt, fistulous pial arteriovenous malformation (Fig. 1), especially when present in child- 
hood, can lead to psychomotor developmental retardation, cardiac insufficiency and, when present later in life, to dementia, and therefore merits treatment [16]. Endovascular treatment should be aimed in these cases at reducing the arteriovenous shunt. Venous congestion (Fig. 2), which can be due to a high input (fistulous lesions) or a reduced outflow (secondary stenosis of the outflow pattern), may be accompanied by a cognitive decline or epilepsy, and we would propose treatment in these cases, with the same aim as stated above [17]. Even if signs of venous congestion are not present, a long pial course of the draining vein may indicate that venous drainage restriction is present over a large area, increasing the risk of venous congestion and subsequent epilepsy. Conversely, a short vein that drains almost directly into a dural sinus is unlikely to interfere with the normal pial drainage. If a patient was to have epilepsy in this kind of angioarchitecture, MRI should be scrutinised for signs of perinidal gliosis. While in the former case (epileptic patient harbouring an AVM with a long pial draining vein), endovascular treatment is warranted to reduce the interference with the normal pial drainage and is likely to reduce the seizure frequency or severity, in the latter cases (epilepsy following perinidal gliosis), endovascular therapies are unlikely to change the seizure frequency or severity, and we would suggest abstention from an endovascular treatment. Mass effect is a rare pathomechanism that may result from large venous ectasias or the nidus proper compressing critical structures, and may lead to epilepsy, neurological deficits and even hydrocephalus (Fig. 3) [18]. Arterial steal has been associated with clinical findings such as migraine and focal neurological symptoms that most often are transitory in nature [19]. With the advent of new imaging techniques such as functional MRI and perfusion weighted MRI, it has now become possible to visualise, whether or not the symptoms of a patient can be attributed to a true steal that can be treated by endovascular means with the aim of reducing the shunt if the symptoms are disabling.

\section{Angioarchitectural classification of brain AVMs}

As outlined above, in non-ruptured AVMs the first step is to evaluate whether the specific symptoms of an individual patient can be related to the AVM; second, one has to evaluate whether the pathomechanism responsible for the symptoms can be treated by endovascular means (as was also described above). The third step consists in evaluating the angioarchitecture of the AVM to determine whether endovascular therapies are suitable for a specific brain AVM and whether there are any focal weak points within the AVM of an asymptomatic patient.

\section{Focal weak points}

The basic principle of the concept of "partially targeted embolisation" of brain AVMs is the hypothesis that specific angioarchitectural features of a pial brain AVM can be regarded as "weak points" that may predispose a patient to haemorrhage [20-22]. While not proven by randomised prospective trials, this principle has been used in our practice for more than 20 years, and we were able to show an improved outcome on follow-up when compared with the natural history [23]. These angioarchitectural weak points are (1) intranidal aneurysms and venous ectasias [24], and (2) venous stenosis [21]. The first to state that a specific angioarchitecture present in brain arteriovenous malformations makes them more prone to future haemorrhage were Brown et al. in 1988, who found that the annual risk of future haemorrhage was 3\% in brain AVMs alone and $7 \% /$ year in brain AVMs with associated aneurysms [12]. Meisel et al. found that among 662 patients with AVMs, there were 305 patients with associated aneurysms, and there was a significant increase in rebleed episodes in AVMs harbouring intranidal aneurysms $(p<0.002)[24]$. In the Toronto series of 759 brain AVMs, associated aneurysms were statistically significantly $(p=0.015)$ asso-
Fig. 1 Fistulous pial arteriovenous malformation with a high-flow shunt. Although they typically present in early childhood when they classically lead to psychomotor developmental retardation or cardiac insufficiency, they can also present later in life; this typically happens with signs of venous congestion, i.e., epilepsy, or even a cognitive decline. Multiple shunts of this type are characteristic of HHT (hereditary haemorrhagic telangiectasia)

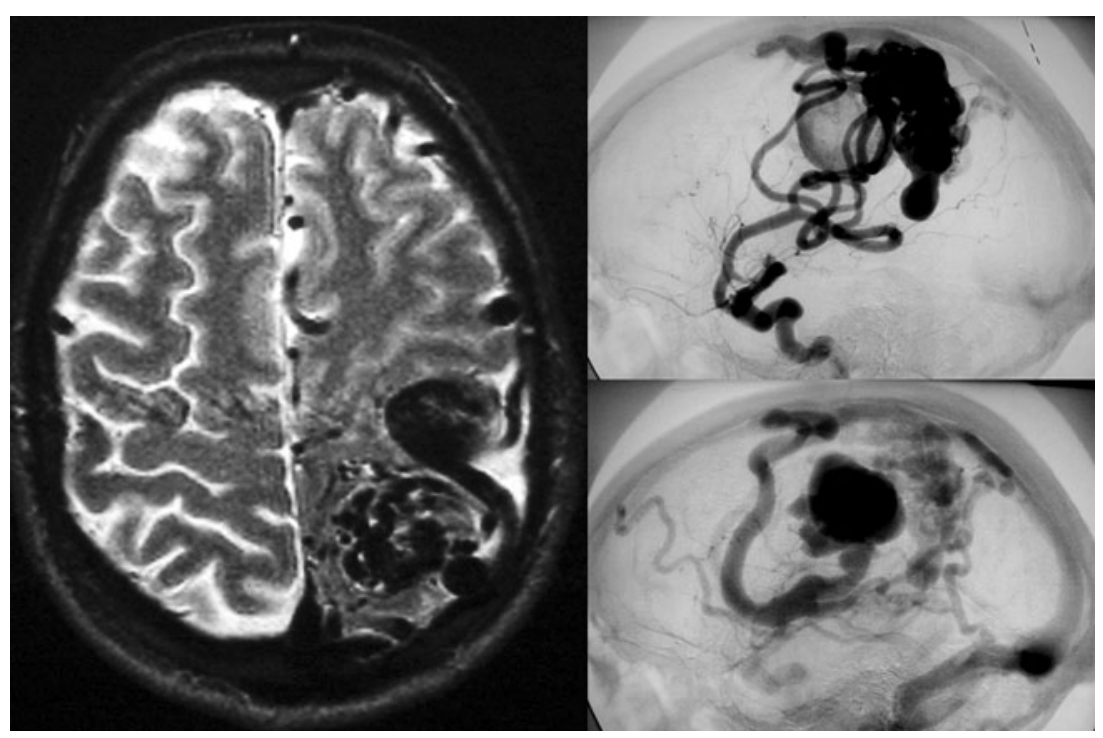


Fig. 2 Three-dimensional venous angiogram and venous phases of an ICA injection demonstrate the classical pseudophlebitic aspect of enlarged and tortuous pial veins as a sign of longstanding venous congestion that may be accompanied by epilepsy, headaches, cognitive decline and focal neurological deficits

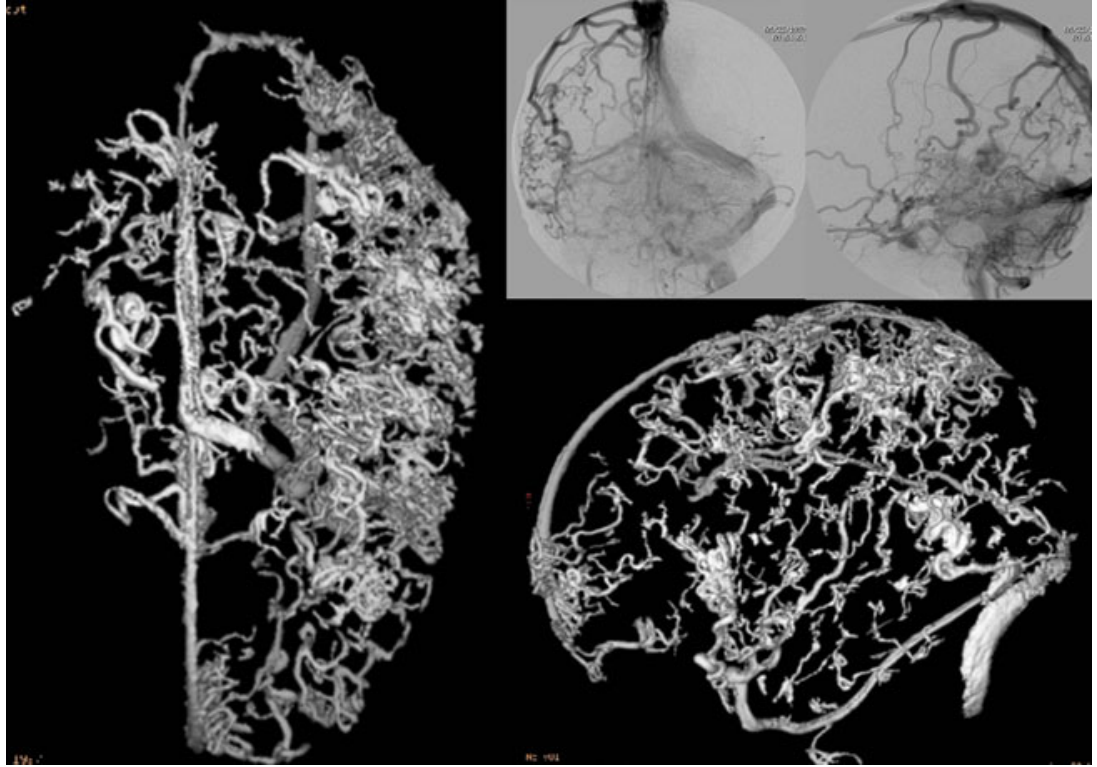

ciated with future bleeding [25]. It may be difficult to discern intranidal arterial aneurysms from intranidal venous ectasias (Fig. 4), which is why these two angioarchitectural specificities are grouped as one entity in most series. Venous stenoses, on the other hand, are a separate angio- graphic weak point and are often seen in ruptured AVMs (Fig. 5). The nature of the venous stenosis is not completely understood; most likely, high-flow vessel wall changes or failure of remodelling (for example, an increased vessel wall response to the shear stress induced by the arterialisa-

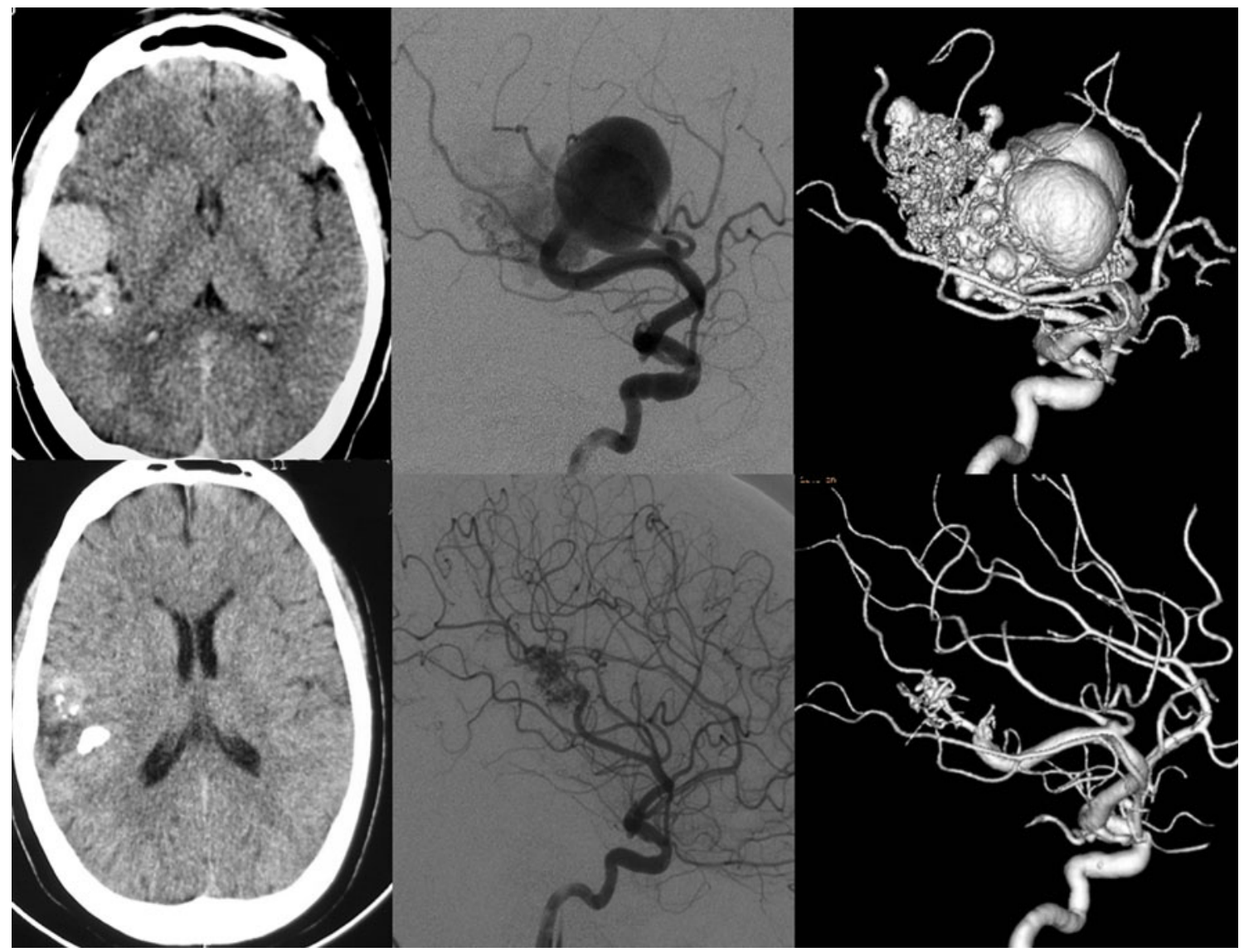

Fig. 3 In rare cases, mass effect of the nidus proper or, as was present in this case, of the dilated draining vein can lead to neurological deficits or, as in this case, seizures. Following partial treatment with embolisation of the large shunt, the size of the venous pouch regressed, the seizures stopped and the remaining small nidus was treated with radiosurgery 
Fig. 4 In this patient with an acutely ruptured AVM, CTA demonstrates an aneurysm pointing into the haemorrhagic cavity as the most likely source of the bleeding. These focal points of weakness can be targeted by embolisation to secure the AVM in the acute phase

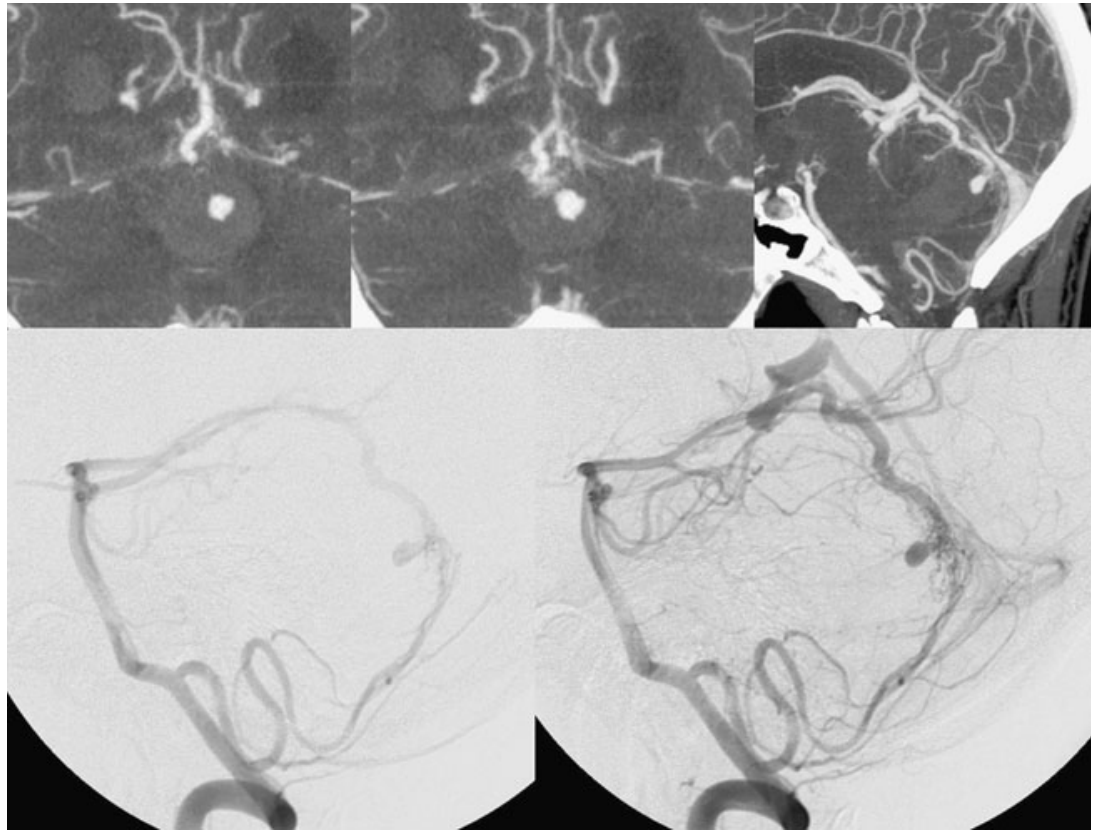

tions) may be put forward as potential reasons. A stenotic venous outlet will lead to an imbalance of pressure in various compartments of the AVM, which may induce subsequent rupture of the AVM. The compartment that is drained by the stenotic vessel should be scrutinised for contrast material stagnation and, if endovascular therapy is contemplated, extreme caution has to be undertaken not to push the liquid embolic agent towards the already stenosed vein as this may have catastrophic results. In addition to these two angioarchitectural risk factors, there are also other factors that may lead to an increased risk of haemorrhage. These are: deep venous drainage only, advanced age and male gender [26].

\section{Angioarchitecture related to endovascular therapies}

Before contemplating therapy of an AVM, the angiography must be scrutinised for the following points: the nature and number of the feeding arteries, the presence or absence of flow-related aneurysms, the number of separate compartments of the malformation, any arterial or venous ectasias near to or within the malformation, and the nature of the venous drainage. On the arterial side, flow-related aneurysms are typically present at branching points of the major feeding arteries. They classically resolve following treatment of the AVM and are due to vascular remodelling following increased shear stress [27]. Although not a contraindication for endovascular treatment, they present a danger to the neurointerventionalist, because flow-directed catheters are prone to entering the aneurysm rather than the distal vessels. Concerning the arterial side of the AVM, both the number and the nature of the feeding arteries need to be assessed as they determine whether endovascular approaches will make sense. A large number of only slightly dilated feeders will make an endovascular therapy more challenging than those with a single large feeder [28]. Concerning the nature of the feeding artery, there are two basic types of feeding arteries. Direct arterial feeders end in the AVM. Indirect arterial feeders supply the normal cortex and also supply the AVM "en passage" via small vessels that arise from the normal artery. While direct feeders are safe targets for an endovascular therapy (Fig. 6), en passage feeders may carry the risk of inadvertent arterial glue migration to distal healthy vessels (Fig. 7). In this regard, the "security margin" of the catheter position has to be briefly discussed. Liquid embolic agents may cause reflux at the end of the injection. Depending on the agent, the microcatheter, the injection technique and the skills of the operator, this reflux may be as far as $1 \mathrm{~cm}$ proximal to the tip of the catheter. A safe deposition of liquid embolic agent is therefore only possible if the catheter tip is distal enough to be beyond any vessel that supplies normal brain tissue. In the case of en passage feeders, this may not be the case, especially if the catheter is only hooked into the feeding artery and will jump backwards because of the jet effect when injecting a liquid embolic agent. Concerning the angioarchitecture of the nidus, intranidal arterial aneurysms and venous varices that indicate weak points need to be recognised as well as the number of compartments and their nature (nidal vs. fistulous). Finally, on the venous side of the AVM, the number of draining veins per compartment (the more the better for endovascular treatment if venous migration should occur), possible drainage into the deep venous system (higher risk of haemorrhage, more difficult surgical treatment) and stenosis, which restrict venous outflow, have to be identified to fully determine the risk of a specific AVM. At the present time, this information can only be obtained by 
Fig. 5 The pathomechansim of this ruptured AVM is presumably due to the stenosis of the major venous outlet (arrow), which led to increased pressure within the nidus proper. If endovascular therapy is contemplated in cases like these, extreme caution has to be taken that no embolic material penetrates too far into the venous side which would lead to further obstruction of the venous outflow
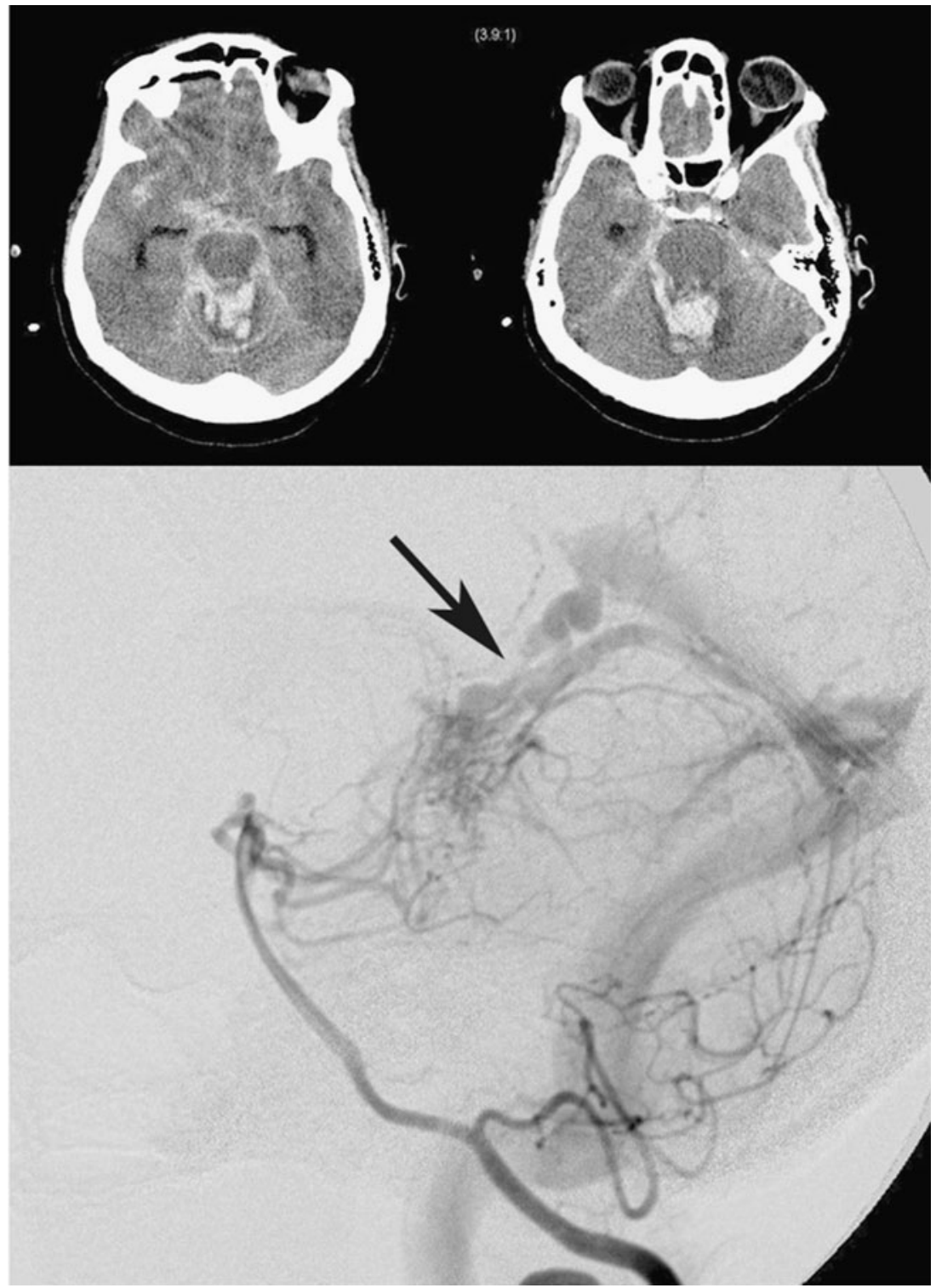

conventional digital subtraction angiography, which in our practice still precedes any treatment decision in AVMs.

\section{Concepts of partial targeted embolisation treatment of brain AVMs}

A complete cure of a pial brain AVM by endovascular means is possible in approximately $20 \%$ of all AVMs irrespective of their angioarchitecture [29-31]. Those AVMs that are favourable to a complete cure are the small, single-feeder, single-compartment AVMs that have a direct feeding artery. As these AVMs are also good candidates for both radiosurgery and open neurosurgery, a tailored team approach for each specific AVM in each individual patient, also respecting his or her wishes and the peculiarities of the clinical presentation, will need to be considered. In most instances, endovascular therapies will be used to diminish the size of an AVM before radiotherapy or surgery, to secure focal weak points in the acute and subacute stage of ruptured AVMs and in unruptured AVMs where radiosurgery is contemplated, or to exclude those compartments of an AVM that may be difficult to reach during surgery. It has to be stressed at this point that, once therapy of an AVM is contemplated, a pathway to its complete occlusion has to be agreed upon by the treatment team, which should include radiosurgeons, vascular neurosurgeons, neurologists and neurointerventionalists. It does not make sense in our opinion to partially treat an AVM without a strategy on how to handle a possible residual of the AVM.

Once endovascular therapy is decided upon, we proceed with a predefined goal, which may mean performing what 
Fig. 6 Single-feeder AVMs are easier to embolise with a higher chance of a complete cure compared with multifeeder AVMs. In this single compartment AVM, the microcatheter is brought to an intranidal position where a histoacryl deposition was able to completely occlude the AVM

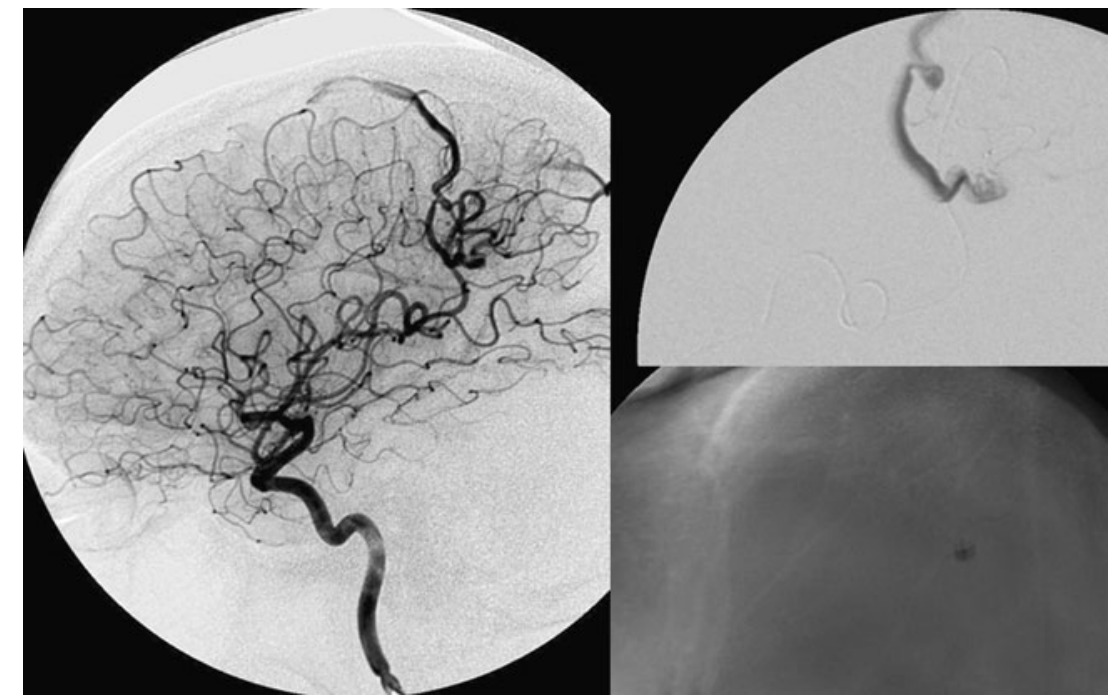

has been coined a partially, targeted embolisation. Such a rationale is based on the outcome of a series of more than 600 patients with AVMs that were partially embolised and showed a significant decrease in haemorrhagic episodes when compared with the conservatively treated series reported in the literature [23]. The yearly haemorrhage incidence rate of patients before partial treatment was 0.062 [95\% CI $(0.03,0.11)]$. The observed annual rate after the start of this regimen was 0.02 [95\% CI $(0.012,0.030)]$ [23]. Given the above-mentioned considerations concerning focal weak points, we think that these numbers reflect the benefit of selectively excluding specific weak compartments of an AVM thereby providing early protection while being scheduled for radiotherapy (whose effects take more time but whose results concerning complete obliteration are better). In these instances the goal is to secure the AVM during its time to complete occlusion. In other instances the goal may be to preoperatively exclude those compartments that will be difficult to reach during surgery or to diminish the size of the AVM before radiosurgery. In the latter instances, compartments in the periphery of the AVM have to be targeted, whereas in the former instances, the neurosurgeon has to point out the target to the neurointerventionalist. Because in combined therapies (endovascular + radiotherapy; endovascular + surgery) the relative risks of each procedure are cumulative, embolisation only makes sense if a goal is predefined before the therapy. In most instances, this goal should be reached during a maximum of two to three endovascular sessions. For most glomerular pial AVMs, liquid embolic materials are the first choice of treatment. The therapy is done under general monitored neuroanaesthesia. We classically use a 5F guiding catheter, which is placed into the distal ICA or VA. A flowdirected microcatheter is then advanced and directed with a microguidewire or gentle contrast material injections into the feeding artery and into the nidus proper using roadmap or fluoroscopy techniques. Here a wedged position of the catheter tip is sought, paying careful attention that there are no normal brain-supplying arteries distal to or in close proximity to the tip of the catheter. After test injections and preparation of the catheter, the liquid embolic material is injected into the nidus, while paying careful attention to avoid venous migration. Depending on the type of embolic agent and the nidus (fistulous versus nidal), the injection techniques will vary. To prevent venous migration, temporary lowering of the blood pressure or compression of jugular veins may be done. To date, there is an ongoing debate as to what kind of liquid embolic agent to use. Personal experience of the authors as well as published data demonstrates a higher rate of complete obliteration with the use of Onyx (40-60\%), but with a significantly increased treatment-associated risk of permanent morbidity and

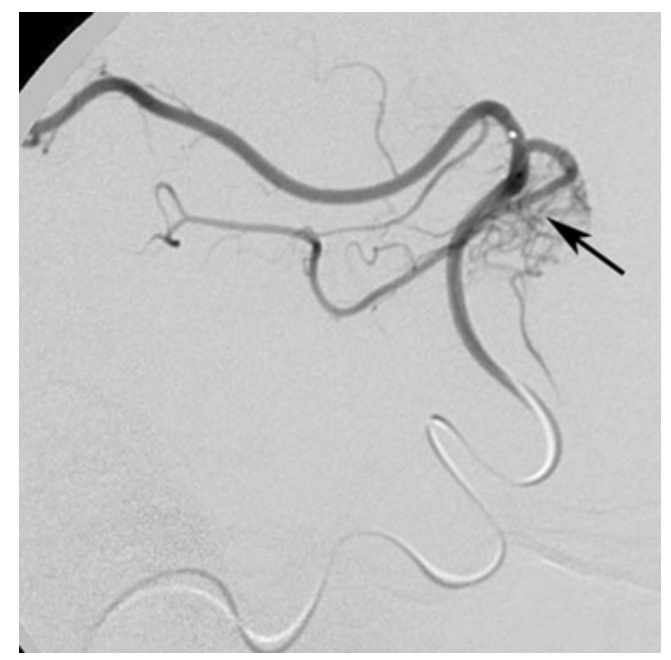

Fig. 7 Whereas the feeder type in Fig. 6 was of the terminal or "direct" type, the feeder type of this AVM is of the "indirect" or "en passage" type. These "en passage" feeders may carry the risk of inadvertent arterial glue migration to distal healthy vessels and in our opinion speak strongly to contraindicate an endovascular treatment approach 
mortality $(8-12 \%)[32,33]$. Following an uneventful procedure the patient is awakened and monitored for 24 $\mathrm{h}$, after which discharge of the patient can be proposed.

A proximal occlusion of feeding arteries without penetration of the embolic material to and just beyond the site of the shunt will lead to reopening of the nidus via leptomeningeal collaterals and may induce a profound neoangiogenesis, which should therefore be avoided, because subsequent endovascular therapies will not be possible. In addition, the profound neoangiogenesis will make discrimination between the nidus proper and normal brain-supplying arteries nearly impossible. In the opinion of the authors, coils and microcoils are therefore not indicated for nidal type AVMs. It is only in certain single-hole macrofistulae that these embolisation materials have a place. Likewise, particles, especially if chosen too large, may lead to an occlusion that is too proximal with subsequent neoangiogenesis. In addition, particles do not necessarily result in a stable occlusion in pial brain AVMs.

Open Access This article is distributed under the terms of the Creative Commons Attribution Noncommercial License which permits any noncommercial use, distribution, and reproduction in any medium, provided the original author(s) and source are credited.

\section{References}

1. Weber W, Kis B, Siekmann R, Jans P, Laumer R, Kühne D (2007) Preoperative embolization of intracranial arteriovenous malformations with Onyx. Neurosurgery 61:244-252

2. Spetzler RF, Martin NA (1986) A proposed grading system for arteriovenous malformations. J Neurosurg 65:476-483

3. Krings T, Geibprasert S, Luo CB, Bhattacharya JJ, Alvarez H, Lasjaunias P (2007) Segmental neurovascular syndromes in children. Neuroimaging Clin N Am 17:245-258

4. Lasjaunias P (2000) Segmental identity and vulnerability in cerebral arteries. Intervent Neuroradiol 6:113-124

5. Lasjaunias P, Ter Brugge K, Berenstein A (2006) Surgical neuroangiography part 3: clinical and interventional aspects in children, 2nd edn. Springer, Berlin

6. Lasjaunias PL, Berenstein A, terBrugge K (2001) Surgical neuroangiography, vol. 1. Clinical vascular anatomy and variations. Springer, Berlin

7. Geibprasert S, Pongpech S, Jiarakongmun P, Shroff MM, Armstrong DC, Krings T (2010) Radiologic assessment of brain arteriovenous malformations: what clinicians need to know. Radiographics 30:483-501

8. Houdart E, Gobin PY, Casasco A, Aymard A, Herbreteau D, Merland JJ (1993) A proposed angiographic classification of intracranial arteriovenous fistulae and malformations. Neuroradiology 35:381-385
9. Valavanis A, Schubiger O, Wichmann W (1986) Classification of brain arteriovenous malformation nidus by magnetic resonance imaging. Acta Radiol 369:86-89

10. Graf CJ, Perret GE, Torner JC (1983) Bleeding from cerebral arteriovenous malformations as part of their natural history. J Neurosurg 58:331-337

11. Crawford PM, West CR, Chadwick DW, Shaw MD (1986) Arteriovenous malformations of the brain: natural history in unoperated patients. J Neurol Neurosurg Psychiatry 49:1-10

12. Brown RD Jr, Wiebers DO, Forbes G, O'Fallon WM, Piepgras DG, Marsh WR, Maciunas RJ (1988) The natural history of unruptured intracranial arteriovenous malformations. J Neurosurg 68:352-357

13. Ondra SL, Troupp H, George ED, Schwab K (1990) The natural history of symptomatic arteriovenous malformations of the brain: a 24-year follow-up assessment. J Neurosurg 73:387-391

14. Mast H, Young WL, Koennecke HC, Sciacca RR, Osipov A, Pile-Spellman J, Hacein-Bey L, Duong H, Stein BM, Mohr JP (1997) Risk of spontaneous haemorrhage after diagnosis of cerebral arteriovenous malformation. Lancet 350:1065-1068

15. Stapf C (2010) The rationale behind " $A$ Randomized Trial of Unruptured Brain AVMs" (ARUBA). Acta Neurochir 107:83-85

16. Krings T, Chng SM, Ozanne A, Alvarez H, Rodesch G, Lasjaunias PL (2005) Hereditary hemorrhagic telangiectasia in children: endovascular treatment of neurovascular malformations: results in 31 patients. Neuroradiology 47:946954

17. Alvarez H, Garcia Monaco R, Rodesch G, Sachet M, Krings T, Lasjaunias P (2007) Vein of galen aneurysmal malformations. Neuroimaging Clin $\mathrm{N}$ Am 17:189-206
18. Geibprasert S, Pereira V, Krings T, Jiarakongmun P, Lasjaunias $\mathrm{P}$, Pongpech S (2009) Hydrocephalus in unruptured brain arteriovenous malformations. pathomechanical considerations, therapeutic implications and clinical course. J Neurosurg 110:500-507

19. Monteiro JM, Rosas MJ, Correia AP, Vaz AR (1993) Migraine and intracranial vascular malformations. Headache 33:563-565

20. Alexander MJ, Tolbert ME (2006) Targeting cerebral arteriovenous malformations for minimally invasive therapy. Neurosurgery 59(5 Suppl 3): S178-S183, discussion S173-113

21. Hademenos GJ, Massoud TF (1996) Risk of intracranial arteriovenous malformation rupture due to venous drainage impairment. A theoretical analysis. Stroke 27:1072-1083

22. Mansmann U, Meisel J, Brock M, Rodesch G, Alvarez H, Lasjaunias P (2000) Factors associated with intracranial hemorrhage in cases of cerebral arteriovenous malformation. Neurosurgery 46:272-279, discussion 279-281

23. Meisel HJ, Mansmann U, Alvarez H, Rodesch G, Brock M, Lasjaunias P (2002) Effect of partial targeted Nbutyl-cyano-acrylate embolization in brain AVM. Acta Neurochir 144:879887, discussion 888

24. Meisel HJ, Mansmann U, Alvarez H, Rodesch G, Brock M, Lasjaunias P (2000) Cerebral arteriovenous malformations and associated aneurysms: analysis of 305 cases from a series of 662 patients. Neurosurgery 46:793-800, discussion 800-792 
25. Stefani MA, Porter PJ, terBrugge KG, Montanera W, Willinsky RA, Wallace MC (2002) Angioarchitectural factors present in brain arteriovenous malformations associated with hemorrhagic presentation. Stroke 33:920-924

26. Hofmeister C, Stapf C, Hartmann A, Sciacca RR, Mansmann U, terBrugge K, Lasjaunias P, Mohr JP, Mast H, Meisel J (2000) Demographic, morphological, and clinical characteristics of 1,289 patients with brain arteriovenous malformation. Stroke 31:1307-1310
27. Krings T, Geibprasert S, Pereira V, Lasjaunias P (2008) Aneurysms. In: Naidich T (ed) Neuroradiology of the brain and spine. Elsevier, New York

28. Willinsky R, TerBrugge K, Montanera W, Wallace C, Aggarwal S (1992) Micro-arteriovenous malformations of the brain: superselective angiography in diagnosis and treatment. AJNR Am J Neuroradiol 13:325-330

29. Richling B, Killer M (2000)

Endovascular management of patients with cerebral arteriovenous malformations. Neurosurg Clin N Am 11:123-145, ix

30. Valavanis A, Yasargil MG (1998) The endovascular treatment of brain arteriovenous malformations. Adv Tech Stand Neurosurg 24:131-214

31. Yu SC, Chan MS, Lam JM, Tam PH, Poon WS (2004) Complete obliteration of intracranial arteriovenous malformation with endovascular cyanoacrylate embolization: initial success and rate of permanent cure. AJNR Am J Neuroradiol 25:1139-1143
32. Katsaridis V, Papagiannaki C, Aimar E (2008) Curative embolization of cerebral arteriovenous malformations (AVMs) with Onyx in 101 patients. Neuroradiology 50:589-597

33. Taylor CL, Dutton K, Rappard G, Pride GL, Replogle R, Purdy PD, White J, Giller C, Kopitnik TA Jr, Samson DS (2004) Complications of preoperative embolization of cerebral arteriovenous malformations. J Neurosurg 100:810-812 